\title{
MODELO DE PARTICIPAÇÃO POPULAR NA MEDIAÇÃO AMBIENTAL E FUNDIÁRIA NO BRASIL
}

\section{Model of popular participation in environmental and land mediation in the Brazilian}

\section{Rachel Lopes Queiroz Chacur}

Doutora em Ciências Ambientais - UFSCar (SP, Brasil). Mestre em Direito Processual Civil e Advogada. Estágio doutoral Universidade de Coimbra. Grupo de Pesquisa da Escola Naval de Guerra - ENA Marinha Brasil.

\begin{abstract}
Resumo
O presente trabalho apresenta o modelo de participação popular na mediação ambiental e fundiária no sistema legal e jurídico brasileiro. O objetivo do trabalho é sugerir a implantação de parâmetros de participação dos sujeitos envolvidos no conflito para obterem a solução do problema ambiental e fundiário. A revisão de literatura definem dogmas e regras normativas, legais e jurídicas respaldando a mediação ambiental descrevendo as relações lineares conflitivas. Acrescenta a visão sistêmica de relações sociais devido a origem das causas complexas e seus desdobramentos durante o desenvolvimento das tratativas de negociação e mediação, envolvendo assuntos de ordem ambiental e gestão de conflitos de interesses. Foi utilizada a metodologia de abordagem exploratória pautada em revisão de literatura e pesquisa empírica, com o uso de instrumentos de planilhas Excell e análise de dados públicos coletados de órgãos públicos, pelo período de 5 anos, em uma comarca e cidade do interior do Estado de São Paulo - SP, no Brasil. Os resultados apresentam a inexistência de meios e tratamento adequado de resolução de conflitos lineares judiciais e complexos nos órgãos públicos judiciais e administrativos. A relevância da proposta advém da projeção de um novo modelo de gestão pública ambiental e fundiária pelo instituto da mediação, em favor da solução de problemas complexos, e, por conseguinte contribuindo com o desenvolvimento econômico e social dos municípios brasileiros.
\end{abstract}

Palavras-chave: Conflitos. Mediação. Ambiental. Fundiária.

\section{Abstract}

This paper presents the model of popular participation in environmental and land mediation in the Brazilian legal and legal system. The objective of the work is to suggest the implementation of parameters of participation of the subjects involved in the conflict to obtain the solution of the environmental and land problem. The literature review defines normative, legal and juridical dogmas and rules supporting environmental mediation describing conflicting linear relationships. It adds the systemic view of social relations due to the origin of complex causes and their consequences during the development of negotiation and mediation deals, involving environmental issues and the management of conflicts of interest. An exploratory approach methodology based on literature review and empirical research was used, using Excell spreadsheet instruments and analysis of public data collected from public agencies, for a period of 5 years, in a region and city in the interior of the State of São Paulo. São Paulo - SP, Brazil. The results show the lack of means and adequate treatment to resolve linear and complex judicial conflicts in the judicial and administrative public bodies. The relevance of the proposal comes from the projection of a new model of public environmental and land management by the mediation institute, in favor of solving complex problems, and, therefore, contributing to the economic and social development of Brazilian municipalities.

Keyword: Conflicts. Mediation. Environmental. Land.

\section{Sumário}

1. Introdução; 2. Breve síntese da nova teoria do conceito de conflito ambiental e fundiário; 3. Os modelos de mediação no ordenamento jurídico nacional: uma nova modalidade de mediação fundiária; 4. A proposta de estrutura e organização da Mediação fundiária; 5. Processamento da Mediação fundiária e a participação popular; 6. O modelo de participação popular na mediação ambiental e fundiária; 7. Conclusão; 8. Notas; Referências 


\section{INTRODUÇÃO}

A mudança de paradigma da teoria de conflitos colabora com uma nova visão global de metas e ações preventivas, diagnóstica e prognóstica de solução de problemas ambientais e fundiários dos territórios nacionais. Com foco na participação popular e de todos os agentes públicos e privados envolvidos, como sujeitos de direitos, nas tratativas de solução dos problemas ambientais e fundiários, rompendo com dogmas clássicos de linearidade de relações simples jurídicas nos órgãos públicos e propõe alguns modelos alternativos.

Esse novo modelo de gestão pública traz discussões acerca do assunto da descentralização estatal para a consecução de programas e planos de políticas públicas.

As premissas estudadas e propostas de modelos conferem a autonomia e responsabilidade de cada ente federado, em resolver as questões vinculadas ao êxito de seu programa e planejamento de governo, como um ônus estatal de boa governança de solução de problemas, e não rompe com os limites e estruturas federativo do Estado.

Esse novo movimento cultural e jurídico sensibiliza os sujeitos de direito e todas as autoridades responsáveis pela consecução destas ações de políticas públicas para se atingir a finalidade positiva da mediação ambiental e fundiária, como um instrumento de eficiência na gestão administrativa e judicial dos órgãos públicos nacionais.

Para tanto, o presente trabalho apresenta um modelo de participação popular na solução e resolução destes no sistema nacional.

A proposta é uma síntese e fruto dos resultados alcançados de uma tese de Doutoramento na área delimitada e colabora com a gestão pública e o desenvolvimento econômico, social, científico e tecnológico das cidades brasileiras.

\section{BREVE SÍNTESE DA NOVA TEORIA DO CONCEITO DE CONFLITO AMBIENTAL E FUNDIÁRIO}

Esse novo posicionamento ideológico da concepção de conflito misto ${ }^{1}$ reforça a necessidade de uma abordagem transdisciplinar e multidisciplinar ao tratar das questões ambientais e fundiárias, enfatizando as necessidades de reformulação de planos, programas, estratégias e ações de políticas públicas de desenvolvimento territorial das cidades.

A proposta da inicial da definição da teoria Mista de Conflitos elucida o conjunto de elementos de regras e leis, de forma sistematizada e em rede internas e externas, lineares e complexas, à dependerem do estado e condição concreta da causa e matéria ambiental e fundiária, e, à serem aplicadas pelos órgãos e instituições brasileiras.

A teoria mista do conflito pressupõe elementos essenciais, elementos secundários e elementos de caráter instrumental e subsidiário, com a finalidade de compreensão dos conflitos fundiários urbanos e aplicabilidade dos instrumentos de solução destes.

Em síntese, os elementos básicos são as regras estabelecidas sobre regularização fundiária no ordenamento jurídico nacional, desde que, respeitados os limites do modelo federativo de Estado trazendo como inovação os elementos secundários atinentes ao substrato dos direitos básicos, embasados em experiências dos fatos sociais, ambientais e 
fundiários. Acrescenta as responsabilidades dos sujeitos e das autoridades envolvidas com eventual ação e omissão pelos seus agentes e propostas de novas estruturas de poderes administrativos e judicial, agregando o caráter vinculativo, instrumental e regulador das decisões sobre os conflitos fundiários urbanos brasileiros.

A definição de conflito misto observa a descrição de todos esses elementos essenciais e fatores correlatos ao objeto demandando da mais variadas naturezas, obedecendo-se as regras consolidadas do instituto e acrescenta às questões estruturais da competência e da função das instituições e entidades envolvidas, no ato resolutivo e vinculativo da solução. Também, acrescenta a proposta de um mecanismo externo regulador de solução do problema ou resolução de conflitos fundiários urbanos na via administrativa e judicial, conforme o procedimento de legitimação fundiária ou possessória e o modelo proposto no trabalho.

Em caráter subsidiário elenca as funções das instituições e do governo, na condução e atuação cooperativa de formas reguladoras e autorreguladoras de conflitos, por meio de uma gestão descentralizada e desconcentrada da Administração do Estado, vislumbrando as atividades de iniciativas pessoais e ações institucionais existentes ou novas no território nacional, aprimorando-se procedimentos de participação e integração de informações tecnológicas de validação e certificação de documentos e títulos de posse e propriedade, sob uma perspectiva cooperativa e sistêmica complexa entre estruturas ou entidades institucionais e não institucionalizadas de uma sociedade, com maior transparência e gestão do tratamento das políticas públicas fundiárias, representadas em fluxogramas de roteirização de instâncias e órgãos de solução e resolução de conflitos fundiários urbanos.

Em sua maioria estes conflitos ambientais e urbanísticos encontram-se sob o viés de rede linear das relações dos legitimados. Geralmente eles são formados em redes lineares com uma subsunção do fato à legislação, assim mantendo o dogma clássico jurídico da concepção de conflito atrelado estritamente a expressa literalidade de normas jurídicas, resultando em decisões meramente declaratórias, mantendo o distanciamento dos problemas e soluções das questões fundiárias das cidades; como descreve o seguinte diagrama (Figura 1).

Figura 1. Diagrama de Rede Linear de Conflitos.

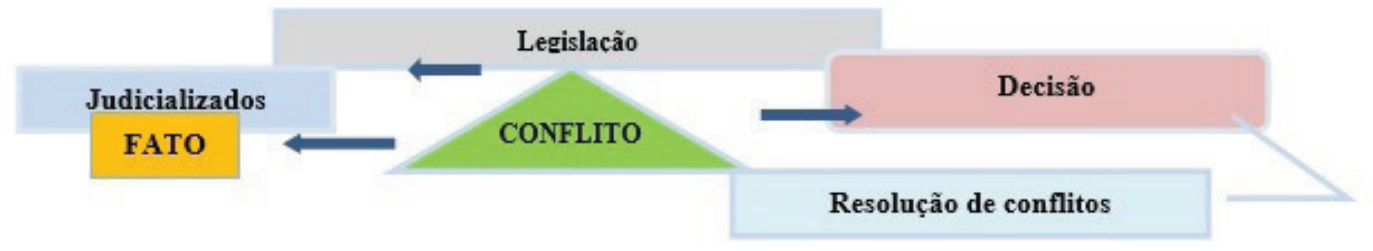

Fonte: Elaborada pela autora.

A figura acima representa uma rede linear de formação de relações de fato e relações jurídicas entre partes opostas envoltas em um determinado conflito de interesses, na sociedade (REALE, 1996).

Essa pretensa relação material e jurídica acarreta inúmeros problemas de ordem interna e externa dos órgãos públicos, trazendo à tona a ineficiência estatal do modelo estru- 
tural-funcional e a ausência de um sistema de controle de litigiosidade fundiária, totalmente desvinculado de atendimento a políticas públicas governamentais de vulneráveis, em suas práticas e rotina forense. Não correspondem aos pedidos dos cidadãos brasileiros e não resolvem o grande número de ações judiciais ou a litigiosidade contida nos órgãos judiciais, assim como, não respondem as exigências dos atos formais convalidados em certidão de posse ou título de propriedade de imóveis ou aos conclâmos do campo fático das tensões e problemas do espaço urbano.

Com a adoção de um novo conceito de conflito faz-se necessário a análise intersistêmica de redes complexas dos elementos singulares com toda a complexidade que forma o sentido da Unidade do sistema, representando a complexidade do diagrama de interconexão de elementos e setores envolvidos nos interesses ambientais e fundiários na sociedade, em contrapartida, a necessária forma de solução do problema ou resolução de conflitos fundiários urbanos (Figura 2).

Figura 2. Diagrama de rede linear Resolução de Problemas fundiários na esfera judicial.

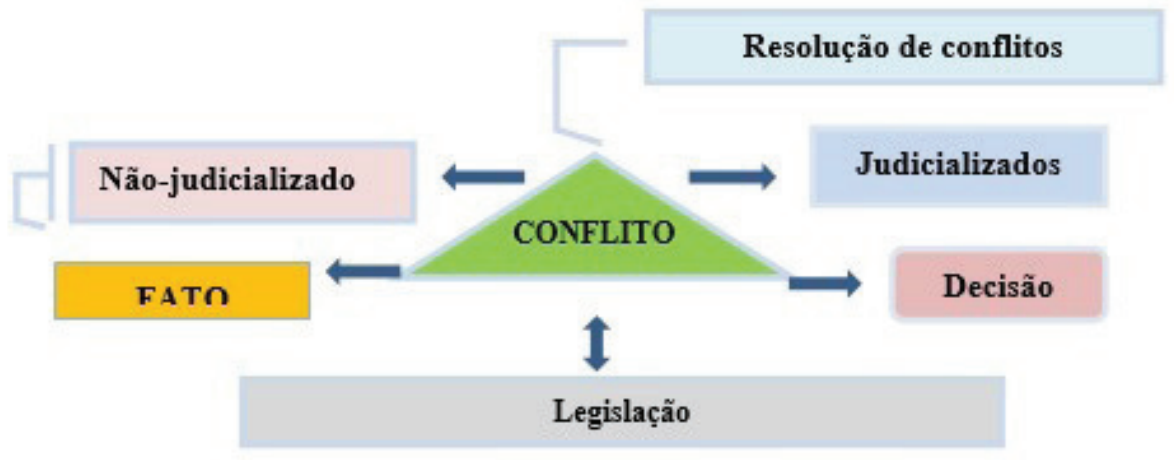

Fonte: Elaborada pela autora.

Com a flexibilização de terminologias e ritos, com o fim de ajustes das lacunas existentes no estrito cumprimento da lei, por meio de comandos diretivos de implantação de modelos, uso de instrumentos e novas práticas de gestão pública participativa, envolvendo entidades públicas e reguladoras ou entidades públicas e privadas, para conferir o resultado da solução dos conflitos não-judicializados e a resolução dos conflitos judicializados no campo dos fatos e na prática forense.

Os conflitos ambientais e fundiários urbanos devem ser resolvidos, ainda que, inicialmente, em redes de lineares, somente na via extrajudicial, de forma menos burocrática e mais racional e objetiva com o uso de instrumentos, processamentos e ritos próprios.

A sugestão de a municipalidade adotar procedimentos padronizados de legitimação de posse e legitimação fundiária urbana, com análise meritória para cada caso de modalidade de Reurb, com a presença de uma equipe multidisciplinar e interdisciplinar entre os técnicos engenheiros, arquitetos, gestores ambientais, agrimensores, entre outros, todos envolvidos com a gestão integrada do setor da Secretaria de Habitação de Meio ambiente e todas as secretarias do Município (MARSHALL, 2002; HIRSCHL, 2004; KMIEK, 2004; BARROSO, 2009; MESSA, 2019).

Esse processamento deve cumprir essas etapas processantes de planejamento pré- 
vio e levantamento diagnóstico ambiental e urbanístico do projeto de regularização ambiental e fundiária, com a submissão e protocolo deste na Prefeitura Municipal. Em tempo hábil de resposta ao cumprimento das etapas de eventuais procedimentos concomitantes administrativos ou judiciários previstos em lei, para se atingir o prognóstico das funções ambientais e estruturas dos imóveis indicados no projeto urbanístico e do espaço urbano da cidade. $\mathrm{E}$, em oportuno momento e fase de planejamento corresponder a demanda da comunidade afetada e das entidades, fazendo-se consulta a toda à sociedade e atribuindo-se as responsabilidades assumidas e compartilhadas, para cada sujeito e órgão.

Este modelo de gestão de conflitos trará os instrumentos e indicadores de qualidade dos serviços ambientais afetando a eficiência de serviços judiciais, resultando em decisões efetivas dos órgãos públicos, no país.

\section{OS MODELOS DE MEDIAÇÃO NO ORDENAMENTO JURÍDICO NACIONAL: UMA NOVA MODALIDADE DE MEDIAÇÃO FUNDIÁRIA}

A mediação é um ato ou efeito de mediar na tentativa de aproximar as partes e colocar se entre os conflitantes da lide, em busca de uma solução ou resolução do conflito de interesse, pela via alternativa e adequada na esfera administrativa ou judicial (Resolução $n^{\circ}$ 45/2008 do Conselho Nacional de Justiça) (CHACUR, 2018).

O instituto da Mediação ultrapassa o conceito de lide conforme apresentada teoria desta tese. Ela demanda uma abertura de diálogos estabelecendo as formas de comunicação entre os envolvidos nas relações conflitivas rompendo com paradigmas de percepções definidas por dogmas, engendrando uma interlocução de troca da fala e ação pelo resultado.

Neste contexto dialético estão os problemas macrossociológicos, como é o caso da regularização fundiária individual e coletiva, em modalidade social ou especial, com o fim de extrapolar as questões jurídicas e resolver a reinserção dos sujeitos ao seu estado natural de direito mínimo de subsistência de direito a moradia e a qualidade de vida.

O modelo de mediação judicial nos procedimentos das normativas processuais vigentes, denominados de Tribunal Multiportas, não resolvem os conflitos fundiários judicializados de direito de primeira grandeza, não correspondendo as exigências específicas do uso de instrumentos urbanísticos e procedimentos e ritos e aos conclâmos do direito ao solo urbano dos locais afetados litigados nas cidades brasileiras (SIX, 2001; ALMEIDA, 2012; CHACUR, 2015).

É preciso uma nova metodologia e rito padrão ajustáveis a regularização da ilegalidade dos imóveis urbanos e regularização ambiental, na prática dos órgãos delegados e judiciais. Esses novos formatos devem acrescentar o ambiente do espaço de representatividade da participação popular no processamento de suas demandas, com a presença dos membros das entidades reguladoras e a primordial atuação do Estado, mediante a interatividade dos órgãos públicos, entidades e sociedade civil solicitando um maior, controle da legalidade do procedimento, da organização e do sistema, permitindo o alcance e uma estabilidade e segurança jurídica das relações imobiliária, em conformidade com o legislado ou contextual fático existente no campo do território. 
No âmbito administrativo e judicial da Mediação devem existir várias formas de participação popular, em suas particulariedades de atividades, níveis e graus, e resultados advindos de trabalhos de estreitamento junto a comunidade afetada, mediante o conjunto de modalidades de mediação comunitária, mediação ambiental, mediação administrativa e mediação fundiária para a solução do problema.

O quadro abaixo demonstra a necessidade de uma forma de comunicação entre todos os interessados pelo direito, pelas entidades representativas, pelos órgãos públicos e pelos setores privados, dentre outros envolvidos na tentativa de solução ou resolução de problemas ambientais e fundiários na estrutura e organização de modelos de mediação administrativa, ambiental e principalmente, mediação fundiária, no país.

Figura 3. Diagrama de Rede Complexa de Resolução de problemas fundiários.

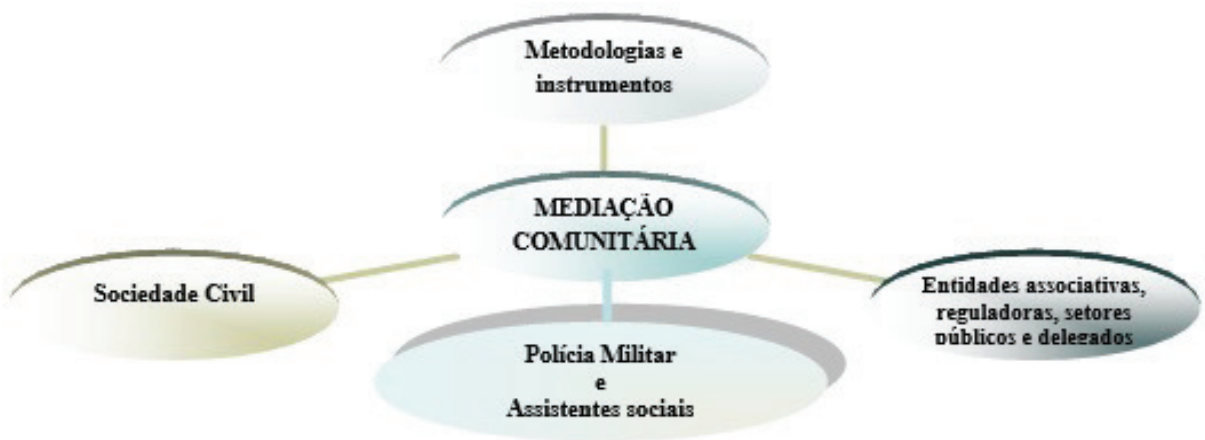

Fonte: Elaborada pela autora.

No âmbito judicial da Mediação deve ocorre a fase pré-processual ou em todas as fases procedimentais, com a sugestão de alterações normativas de previsão de audiências públicas prévias antes de audiências preliminares do rito especial, com a participação do Juiz e Ministério público, para em conjunto com a comunidade afetada intentar um acordo; como demonstrada as fases e etapas no quadro abaixo (Quadro 1).

Quadro 1 - Quadro Comparativo das Etapas da Mediação Judicial e Mediação

Administrativa na regularização fundiária urbana.

\begin{tabular}{|l|l|}
\hline MEDIAÇÃO JUDICIAL & MEDIAÇÃO ADMINISTRATIVA \\
\hline $\begin{array}{l}\text { Fase pré-processual para ações distribuídas ou } \\
\text { retomada de chamada da fase pré-processual para as } \\
\text { ações pendentes. }\end{array}$ & Fase pré-processual. \\
\hline Formas de participação popular. & Formas de participação popular. \\
\hline Acordo ou Processamento judicial. & $\begin{array}{l}\text { Mediação administrativa ou Mediação } \\
\text { fundiária. }\end{array}$ \\
\hline $\begin{array}{l}\text { Litigio forma por meio da ação judicial. } \\
\text { Fases próprias do Rito Especial Usucapião, } \\
\text { Reintegração de Posse, Demarcatória, } \\
\text { Desapropriação, entre outras. }\end{array}$ & $\begin{array}{l}\text { Rito do Cartório de Registro Público de } \\
\text { Imóveis com o procedimento de Averbação } \\
\text { ou Anotação de certidões de legitimação de } \\
\text { posse ou legitimação fundiária. }\end{array}$ \\
\hline $\begin{array}{l}\text { Fase instrutória padrão dos ritos especiais acima } \\
\text { adotados. }\end{array}$ & $\begin{array}{l}\text { Fase de julgamento - Fase Recursal - Fase de } \\
\text { Execução - Fase suspensiva. }\end{array}$ \\
\hline Arquivamento & \\
\hline
\end{tabular}

Fonte: Elaborada pela autora.

É fundamental a reestruturação do processo para as hipóteses de procedimentos 
avançados de desenvolvimento dos atos, em fase probatória ou decisória ou suspensiva do processo judiciais, com enfoque em designar audiência pública, com o intuito de levar ao êxito formas de participação popular, para obter acordos homologados individuais ou coletivos, com efeitos vinculativos fundiários ou remeter ao processamento administrativo.

A sugestão de parcerias de consorcio do setor público e privado, na consecução de regularização fundiária dos imóveis em litigio e entrega da certidão de legitimação possessória ou a escritura do imóvel aos cidadãos atingidos pelo problema fundiário.

Com a ressalva da participação obrigatória do advogado e mediador especializado e capacitado, bem como a representatividade de todas as entidades envolvidas e interessadas na solução do problema ambiental e fundiário, além da presença de representantes do próprio Poder Judiciário e Poder Executivo, bem como órgãos reguladores nas sessões de mediação (TARTUCE, 2016; CHACUR, 2014; CHACUR, 2019; CEBOLA, 2020).

Como suporte desses instrumentos e metodologia também o uso da inteligência artificial, com o uso de mediação online (ADR e ODR), ${ }^{2}$ em todas as formas em separado e as modalidades descritas em tabela própria, porém, conexo de solucionabilidade e do canal de sistemas de comunicação e informações de dados de sistemas validados e certificadas, pelos órgãos públicos e delegados.

Os ritos especiais e procedimentos judiciais utilizados para a resolução e os mecanismos de tratamento de resolução de conflitos ambientais e fundiários judicializados urbanos estão inadequados no sistema de funcionamento e gestão do Poder Executivo e do Poder Judiciário brasileiro (CHACUR, 2012).

A proposta descrita abaixo destaca essa nova modalidade de mediação fundiária, principalmente, dentro das estruturas e funções do Poder Judiciário, nas vias administrativa e judicial; como descreve o fluxograma.

Figura 4. Diagrama de Rede Complexa estrutural judicial de solução de problemas fundiários e delegações de serviços.

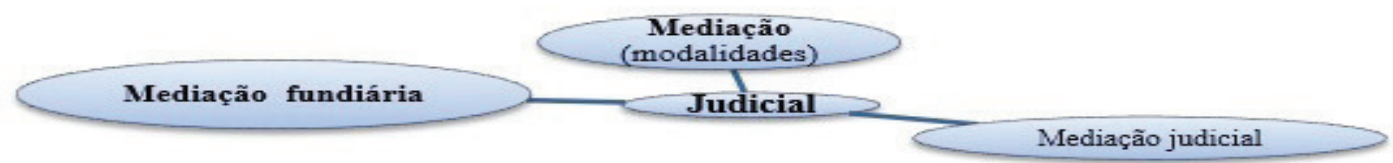

Fonte: Elaborada pela autora.

No caso em tela de mediação em assuntos de regularização ambiental e fundiária urbana resta incluir o uso de instrumentos urbanísticos e novas metodologias de solução e resolução de conflitos judiciais aplicando-se a obrigatoriedade de pré-fases de mediação comunitária, em todas as modalidades e graus de escalas de participação da sociedade civil, com a interlocução da comunidade junto aos órgãos públicos.

Com o apoio das entidades associativas de bairros, participação ativa das Assistentes Sociais, a atuação da Polícia Militar, a presença de representantes dos setores econômicos e sociais e autoridades públicas no ato das negociações e tratativas das mediações fundiárias e ambientais, para a solução destes problemas. 
O modelo autônomo de Mediação fundiária pode aproveitar o misto desse modelo padrão de processamento do conteúdo de ambas as esferas de resolução de conflitos fundiários urbanos, mantendo suas características do processamento de regularização fundiária, com os efeitos vinculativos de suas decisões dirigidas aos órgãos delegados administrativos, com o aproveitamento de atos judiciais e a remessa de informações aos Cartórios de Registro de Imóveis, em favor da economia e eficiência das gestões cartorárias, abaixo demonstrado.

Figura 5. Diagrama de Rede Complexa de Solução de problemas fundiários.

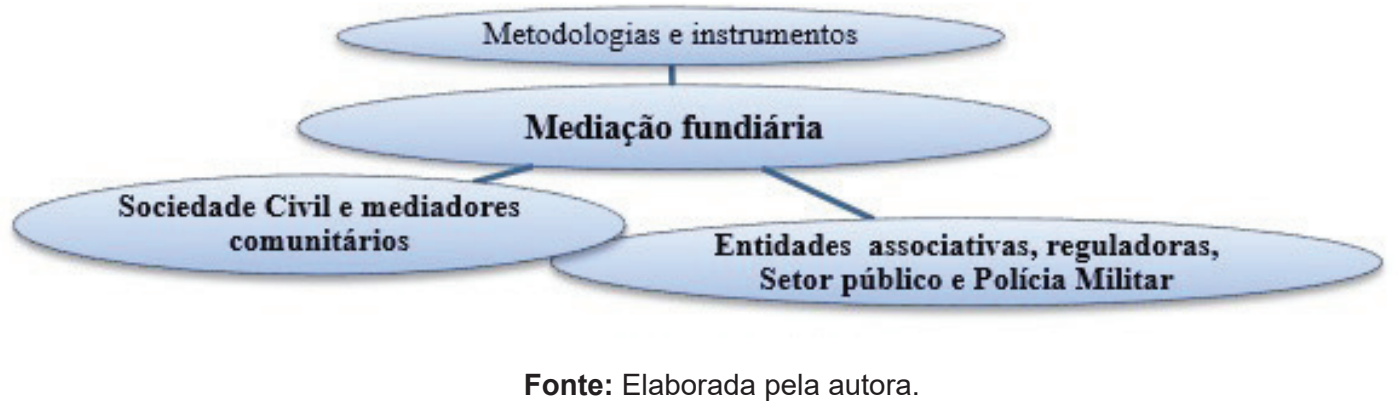

A criação desta modalidade de mediação fundiária requer a aplicação de metodologias e instrumentos ambientais e urbanísticos, em todas as esferas administrativas e judiciais, com o envolvimento dos sujeitos e entidades envolvidas na solução do problema, com o apoio dos órgãos públicos nas instâncias competentes, nas denominadas redes complexas e sistêmicas de solução de problemas.

\section{A PROPOSTA DE ESTRUTURA E ORGANIZAÇÃO DA MEDIAÇÃO FUNDIÁRIA}

Neste processamento de regularização fundiária urbana é preciso criar uma estrutura com atribuições definidas de funções de regularização fundiária, com atos administrativos com efeito vinculativo e informados a atividade gestora de imóveis na Secretaria de Habitação do Município das cidades e integrado com o sistema informatizado do Cartório de Registro de Imóveis Públicos da comarca local e estabelecer vínculos com o sistema informatizado do Poder Judiciário.

Figura 6. Diagrama de Rede Complexa estrutural de Solução de problemas fundiários.

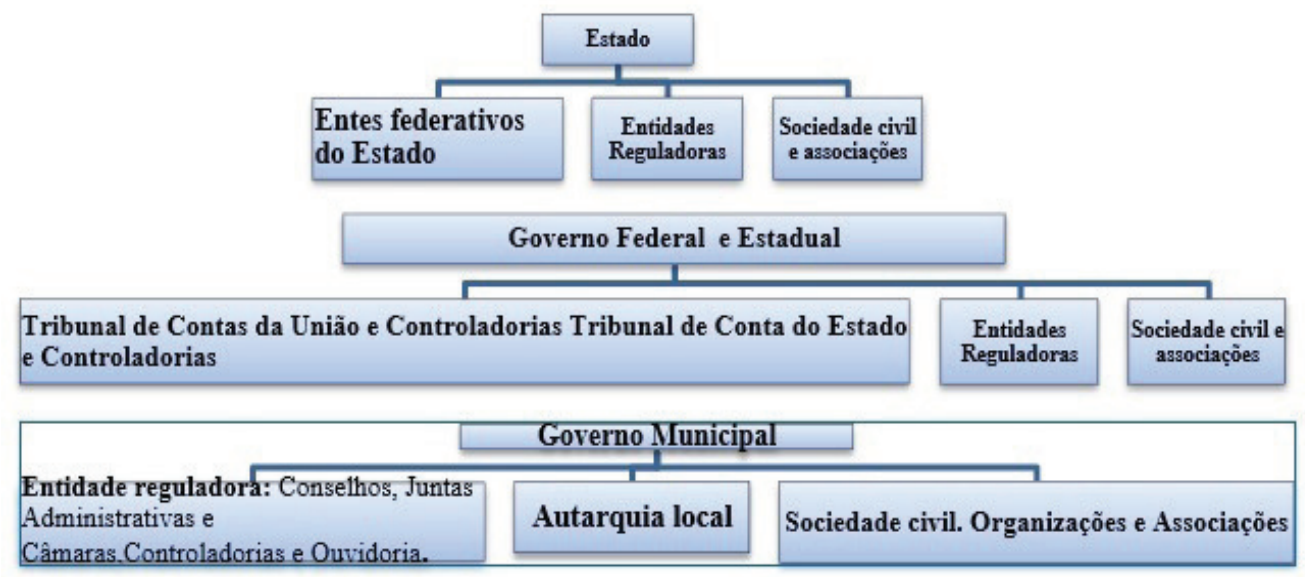

Fonte: Elaborada pela autora. 
Como acima exposto é preciso criar uma reestruturação da organização da Administração Pública direta e indireta centralizada e descentralizada, com a desconcentração de competências e a simplificação de procedimentos, com controladoria de resultados.

A distribuição organizacional de competências e protegendo a sua autonomia interfederativa dos governos na esfera federal, estadual e municipal, porém, para cada qual, propiciando uma rede interativa de canais de comunicação de informações registrais e notariais, com a projeção da viabilidade de implementação de políticas públicas e agendamento de um calendário do planejamento orçamentários de destinação de recursos, para cumprir as metas e ações diretas de regularização fundiária focal.

Os governos manterão a autonomia de gestão e controle financeiro promovendo o repartilhamento de recursos e orçamentos dotados de prévia tomada de preço ou licitação a depender da modalidade da participação da entidade interessada, associação civil ou qualquer cidadão, regulado por esferas hierárquicas superiores em uma interconexão de sistemas fiscalizatórios e reguladores de projetos e serviços de regularização fundiária urbana.

Esta condição de governança interfederativa recairia na indagação sobre a autonomia dos Estados da Federação e manifestação contrária ao controle externo estatal. Ocorre que, em tempos de tecnologia e mutações rápidas de ciclos dinâmicos da vida, em uma rede de informações e interesses múltiplos, com inúmeras pessoas e sujeitos de interesses envolvidos na teia complexa do sistema recomendam-se instrumentos de controle mitigador de possíveis desvios de conduta dos agentes públicos e privados, para atender eventual prática de corrupção sistêmica ou a garantir a proteção do grau de exposição do ente federativo em relações cooperativas, sistemas integrados e redes complexas.

$\mathrm{Na}$ esfera federal além da estrutura organizacional e funcional acima exposta dos estados-membros, a sugestão de criar um orgão descentralizado da Administração Pública, com o fim de regulação das atividades e serviços de regularização fundiária, em um sistema informatizado integrado, vinculados aos Tribunais de Contas e controladorias. De modo a monitorar os programas e projetos pelos meios de inteligência artificial, fornecidos e geridos pelo próprio Estado. Desta feita, informando as movimentações tributárias a todos os órgãos fazendários do fisco, em todo o território nacional; pois não existem redes sistêmicas integradas e compartilhadas de informações destas questões ambientais e fundiárias, e seus reflexos econômicos e fiscais, entre os entes federados e os órgãos fiscalizatórios, para levar-se à cotento, a regularização fundiária urbana e a distribuição econômica, tributária e equitativa das despesas e custos públicos, para o desenvolvimento das cidades e municípios.

Na esfera estatal promover a revitalização das atribuições e competências do Tribunal de Contas do Estado trazendo à tona o debate da forma de indicação de seus membros, com possíveis eleições e participação livre e aberta, também de representantes da sociedade civil. A sugestão é reforçar a autonomia das entidades de controladoria, já existentes nas competências estatais, criando uma nova forma de indicação dos membros da Controladoria do Município e Tribunal de Contas do Estado e Tribunal de Contas da União acrescentando no quadro de participação dos membros dos respectivos tribunais, um representante da sociedade civil ou entidades não governamentais com direito a voto e conferindo a partici- 
pação nos debates, para a votação e aprovação final dos programas e prestação de contas dos recursos públicos. Para tais providencias, é fundamental promover a revitalização das atribuições e competências do Tribunal de Contas do Estado trazendo à tona o debate da forma de indicação de seus membros, com possíveis eleições e participação livre e aberta, também de representantes da sociedade civil.

$\mathrm{Na}$ esfera municipal, a alternativa é a criação de uma autarquia local nos Municípios composta por Entidade reguladora composta por Conselhos, Juntas Administrativas e Câmaras privadas e Controladoria Municipal, cada qual com atribuições e competências com a finalidade específica para receber as inscrições de projetos ou demandas individuais solicitando a regularização fundiária de seu imóvel gerido pelas Prefeituras Municipais, em conjunto, com outras entidades e empresas envolvidas na área e vinculadas as respectivas secretarias da municipalidade (TORRES, 2009; ALVES, 2020). ${ }^{3}$

No caso em tela, ao tratar da temática de Regularização fundiária urbana sugere-se a utilização da terminologia estrutural de Conselhos ou Juntas administrativas de Mediação de conflitos fundiários urbanos, em sede de autarquias municipais vinculadas ao Município.

É importante a criação desta estrutura e funções em redes complexas de trocas de informações e gestão de dados para viabilizar a via alternativa de resolução de conflitos judiciais declinados a via administrativa dos cartórios extrajudiciais e delegados ou respectivas câmaras privadas ou públicas das autarquias municipais. Para aquelas hipóteses que restam somente a via judicial também a alternativa da mediação fundiária em redes complexas estruturais de solução de problemas fundiários, com o suporte de apoio tecnológico, técnico e jurídico de resolução de conflitos fundiários urbanos.

\section{PROCESSAMENTO DA MEDIAÇÃO FUNDIÁRIA E A PARTICIPAÇÃO POPULAR}

Surge um novo modelo a ser testado de participação popular na solução de problemas ambientais e fundiários no Brasil.

A etapa de participação popular deve ser adotada em várias oportunidades e momentos distintos, como imperativo categórico obrigatório de todas as fases do procedimento da REURB- Social ou REURB - Especial, com formatos diversos de comunicação e participação dos afetados e interessados, com agentes condutores diferentes em cada nível e grau de diálogo na sequência dos trabalhos, à depender dos interesses conflitivos e do conflito, e das informações trocadas, provas apresentadas, demandas e interesse público pertinente, com a eventual obrigatoriedade de representação dos legitimados por meio de órgãos estatais (CAFRUNE, 2016; TARTUCCE, 2015; HAMER, 2016).

No tocante, a processamento das fases da Mediação fundiária é obrigatória a audiência pública com a presença dos moradores, os quais terão direito a voto e tomadas de decisões no espaço em semicírculos e redondos, gerando a interação direta de todos os membros da reunião, somente incorrendo em consenso após esclarecidos todos os pontos controvertidos, técnicos e jurídicos consequentes, e resultar em um documento hábil com efeito vinculativo da legitimação possessória ou legitimação fundiária dos imóveis ou geran- 
do um termo de acordo homologado pelo Ministério Público e Poder Judiciário, levando a efeito e êxito o registro no Cartório de Registro Público de Imóveis da circunscrição. Para tanto, é recomendável a utilização de toda a estrutura de rede complexa de solução de problemas fundiários para garantir o êxito de uma iniciativa de modelo de solução de conflitos fundiários urbanos, com resultados positivos de mediação fundiária urbana, evitando a judicialização dos conflitos de interesses e vinculando os atos judiciais e administrativos na via inversa ou versa conforme o momento da fase dos procedimentos de regularização fundiária. Caso haja pendências de conflituosidade de ações judicializadas de conflitos fundiários sugere-se o deslocamento de competências descentralizadas administrativas e a transferência de atribuições de resolução de conflitos na via extrajudicial para a solução de problemas fundiários, com a participação popular em audiências prévia, e, após o resultado, a posterior informação de mediação positiva ou negativa devolvida ao orgão judiciário, para o arquivamento dos autos físicos ou digitais do processo.

Nas situações de mediação fundiária, em caráter autônomo, estabelecer o aceite do processamento duplo nas vias diretas e indiretas, em ritos especiais processados nos órgãos judiciárias e administrativos, o que dependerá de alteração legislativa em ambos os textos normativos das normas internas das esferas administrativas e judiciais, para implantar a base de metodologia de funcionamento e organização da modelagem de mediação fundiária, os canais de sistemas de informação e certificação de registros e validar a base de dados de decisões judicias com efeito administrativo vinculativo, para várias plataformas dos órgãos públicos centralizados ou descentralizados no sistema nacional.

A ressalva é a existência destas iniciativas de reformulação das normas internas do processamento eletrônico de Registros Públicos de Imóveis, porém, não existe a previsão desta proposta de comunicação de processamentos e informações entre os órgãos administrativos, judiciários e delegados, para tal fim de vinculação e efeitos imediatos da decisão, em sede extrajudicial.

Neste sistema de governança compartilhada dos órgãos administrativos e judiciais é fundamental geral um modelo padrão sistêmico de solução de conflitos judicializados e problemas fundiários, à ser adotado como uma política pública nacional de distribuição de solo e regularização fundiária no Brasil.

Como se apresenta o diagrama abaixo descrevendo os atores e envolvidos na solução dos problemas complexos, em uma rede complexa de partes interessadas em todos os graus e níveis de diálogo e tomada de decisão, com responsabilidades individuais e compartilhadas, em proveito do equilíbrio da representatividade, com segurança ao direito dos legitimados, favorecendo o direito e a participação ativa dos cidadãos, contribuindo com o estreitamento da sociedade com os entes representativos das entidades e órgãos públicos, e, entes federativos (Figura 7). 
Figura 7. Diagrama de Rede Complexa Estrutural de Solução de problemas fundiários.

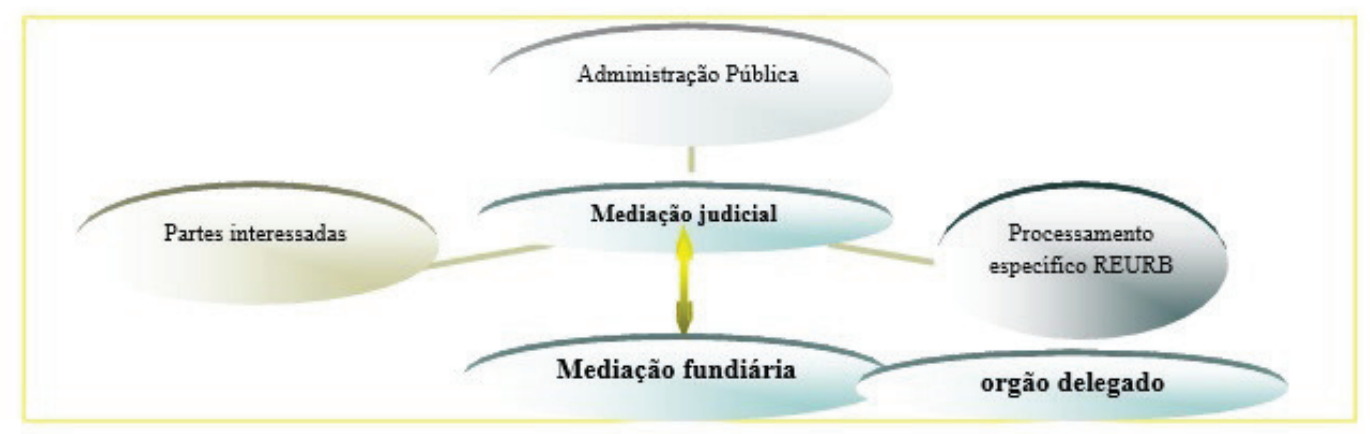

Fonte: Elaborada pela autora.

\section{O MODELO DE PARTICIPAÇÃO POPULAR NA MEDIAÇÃO AMBIENTAL E FUNDIÁRIA}

Os formatos de participação comunitária precedem de planejamento de sessões de entrevistas, fórum, workshop, reunião ou painéis, a depender da especificidade da demanda e complexidade dos sistemas envolvidos no conflito ou problema fundiário e ambiental. $\mathrm{O}$ planejamento de atividades devem indicar previamente o nível de confidencialidade dos interesses em jogo e os limites de sua confidencialidade, e os objetivos para a consecução dos fins propostos de regularização ambiental e fundiária de uma comunidade afetada.

De forma sistemática a participação deve ser circular, colaborativas multiplurais, inclusivas e transparentes levando os atores sociais a uma identificação do problema, elencando as suas necessidades e demandas, em busca das melhores soluções ambientais e urbanísticas, em todas as acimas indicadas fases de decisões sobre o conflito (FISCHER, 1991; LOPES, 2019; CEBOLA, 2020).

Figura 8. Diagrama de Solução de Problemas fundiários na esfera administrativa.

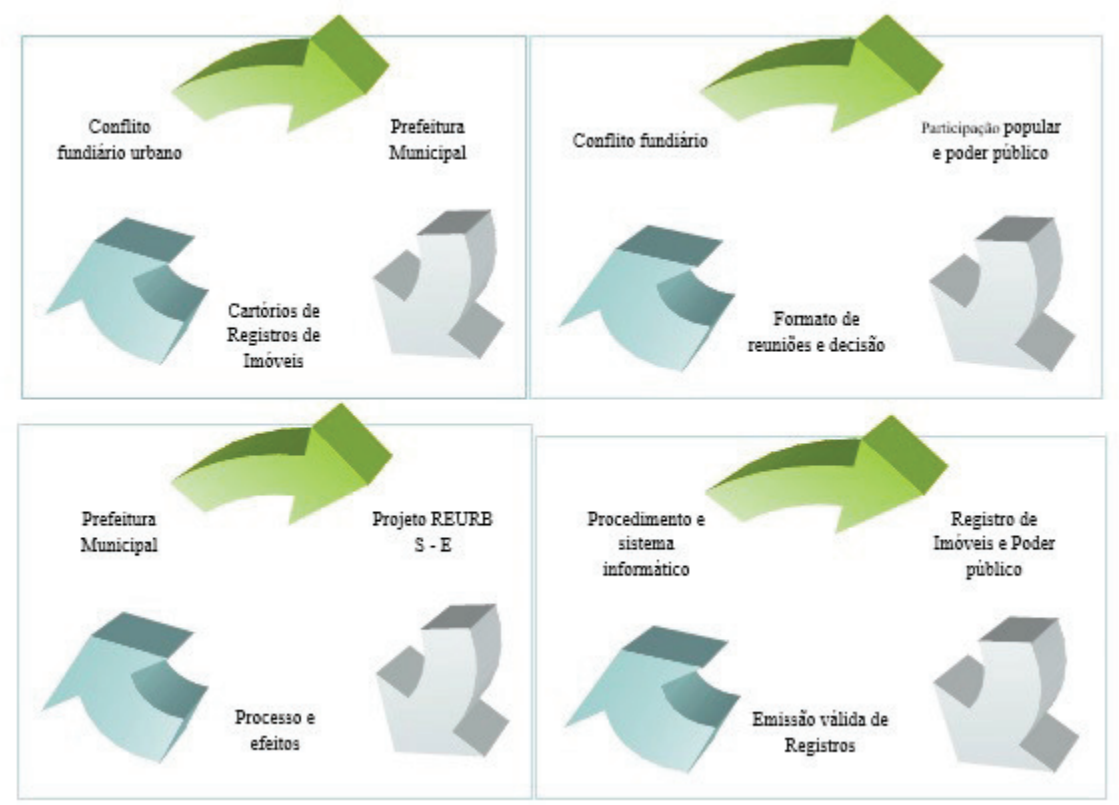

Fonte: Elaborada pela autora. 
Nesta escala e grau de participação popular no processo de regularização fundiária urbana é oportuno utilizar o maior número de mecanismos de projeções narrativas circulares, com um caráter transformativo da fala da ação do sujeito ator de suas próprias histórias e contexto local de moradia (COOB, 2013; BUSH E FOLGER, 2014).

Figura 9. Graus e escalas de Participação popular em Solução de Problemas fundiários.

\begin{tabular}{|c|c|c|c|}
\hline Atividade & Nível de confidencialidade & Objetivo & Gestão de confidencialidade \\
\hline $\begin{array}{l}\text { Entrevistas e } \\
\text { reuniões } \\
\text { individuais com } \\
\text { os interessados }\end{array}$ & Total & $\begin{array}{l}\text { Análise dos interessados } \\
\text { Obtenção de informações } \\
\text { das partes } \\
\text { Inventários e análise das } \\
\text { experiências dos } \\
\text { interessados. }\end{array}$ & $\begin{array}{l}\text { Proteção das informações e } \\
\text { reflexões em espaços internos } \\
\text { de diálogo espontâneo de troca } \\
\text { direta e restrita. }\end{array}$ \\
\hline Encontros & Quase total & $\begin{array}{l}\text { Obtenção da informação } \\
\text { Análise de experiência } \\
\text { Reflexão sobre o } \\
\text { processo } \\
\text { Desenvolvimento de } \\
\text { resultados como inputs } \\
\text { para outras fases. }\end{array}$ & $\begin{array}{l}\text { Proteção das informações e } \\
\text { reflexões em espaços externos } \\
\text { de diálogo com a comunidade } \\
\text { de troca coletiva e quase- } \\
\text { restrita. }\end{array}$ \\
\hline $\begin{array}{l}\text { Painéis com os } \\
\text { grupos de } \\
\text { interessados }\end{array}$ & Variada & $\begin{array}{l}\text { Compilação de } \\
\text { informações especificas } \\
\text { do caso } \\
\text { Exploração de possiveis } \\
\text { articulações e parcerias. }\end{array}$ & $\begin{array}{l}\text { Espaço de intercâmbio de } \\
\text { informações e esclarecimentos } \\
\text { das funções e papeis de cada } \\
\text { interessado ou agente público } \\
\text { envolvido no conflito. }\end{array}$ \\
\hline Fóruns abertos & Nenhuma & $\begin{array}{l}\text { Envolvimento dos } \\
\text { interessados } \\
\text { Garantia de transparência } \\
\text { Fornecimento de } \\
\text { informações } \\
\text { Promoção do debate e da } \\
\text { reflexão entre todos os } \\
\text { interessados } \\
\text { Divulgação dos } \\
\text { resultados. }\end{array}$ & $\begin{array}{l}\text { Espaços abertos com o fito de } \\
\text { trazer os problemas e as } \\
\text { soluções de enfrentamento de } \\
\text { pacificação do conflito } \\
\text { emanando um relatório final } \\
\text { remetido aos interessados e } \\
\text { órgãos públicos envolvidos na } \\
\text { demanda. }\end{array}$ \\
\hline Interação online & Nenhuma & $\begin{array}{l}\text { Alargamento do diálogo } \\
\text { para além dos presentes } \\
\text { eventos } \\
\text { Promoção do } \\
\text { envolvimento entre } \\
\text { eventos. }\end{array}$ & $\begin{array}{l}\text { Espaço democrático e } \\
\text { facilitador de reflexão e troca } \\
\text { de informações abertas de } \\
\text { desafios e metas de } \\
\text { implementação do projeto. }\end{array}$ \\
\hline $\begin{array}{l}\text { Avaliação e } \\
\text { Gestão }\end{array}$ & Nenhuma & $\begin{array}{l}\text { Sistemas internos e } \\
\text { externos de informações } \\
\text { e comunicação de } \\
\text { indicadores de qualidade } \\
\text { de serviços públicos e } \\
\text { demandas focais. }\end{array}$ & $\begin{array}{l}\text { Espaço de informação e } \\
\text { comunicação do sistema e } \\
\text { entre sistemas privados e } \\
\text { públicos gerando vínculos de } \\
\text { efeitos imediatos de validação } \\
\text { da proposta, até findar acordo } \\
\text { homologado ou registro do } \\
\text { direito. }\end{array}$ \\
\hline
\end{tabular}

Fonte: modelo adaptado do Projeto "MAR Gov." e incluído o sistema de gerenciamento de sistema de graus de avaliação da qualidade de serviços públicos e comunicação entre os setores e órgãos públicos administrativos e judicial do Estado nacional.

A estrutura do processo de participação apresenta uma prática desenvolvida em uma proposta do projeto de sessões participativas e modelos cooperativos e sistêmicos do "Projeto MARGOV", realizado pelo governo português. Após a análise dos documentos e relatórios a advertência de utilização da ordem inversa dos níveis de graus de escalada de conflituosidade de Glasl (1980) como pressuposto de ruptura de elos lineares dos conflitos, evitando-se terminologias de endurecimento e de simples grau de debate, para gerar uma rede de polêmica, imagens e signos, coligações de personificação, estratégias de ameaças, 
aniquilamento do inimigo e estilhaçamento do inimigo para o abismo, até se chegar ao caos do entendimento do conflito, para elencar as opções de solução do problema (GLASL, 1980; FONSECA, 2010; ALUTT, 2015, VASCONCELOS, 2016). ${ }^{4}$

No processamento documental das reuniões junto à comunidade local afetada, devem ser exigidas as mínimas formalidades de validade e efeitos da tomada de decisão, com total transparência e votação dos presentes, em caráter de tomada de decisões unânimes ou em maioria qualificada nos fins das sessões. Com o início de carta convite aos membros de lista prévia de levantamento do número de interessados domiciliados e as condições ambientais e urbanísticas de cada imóvel ou local habitado, assim indicando nominalmente os legitimados, para se obter um panorâma do grau e escala de conflituosidade ambiental, urbanística e social, daquela comunidade. Nestas reuniões é fundamental promover um espaço democrático de voluntariedade individual e completa de participação dos interessados nas audiências públicas fomentando os diálogos e a abertura da fala para a projeção dos pedidos do local afetado, com a participação voluntária condicionada ou forçada de entidades representativas, as quais trarão sugestões de possibilidades de condução de tratativas, daquilo que pode ser negociado e àquilo que invariavelmente será objeto de ações de programas de políticas públicas do poder público (CEBOLA, 2020).

Esses níveis são classificados pelos parâmetros de voluntariedade completa, parcial, condicionada ou forçada e depende do grau de confiança no processo conduzido pelos facilitadores e agentes públicos.

\section{CONCLUSÃO}

Diante do caráter científico da tese apresentadas as propostas das premissas teóricas dos fundamentos de teoria mista do conflito em redes complexas, com modelos de processamentos de modos autônomo ou híbrido à depender da classificação do conflito judicializado ou não-judicializado, com uma visão macro-etnográfica das disputas sociais e judiciais, embasadas na dogmática positivista e jurídica, o surgimento de novas modalidades de mediação, inclusive, a modalidade da mediação fundiária, no Brasil.

Apesar de inúmeras legislações atualizadas sobre a linha temática e o assunto da regularização fundiária no sistema jurídico-legal brasileiro, carecem de rupturas dogmáticas, novas metodologias, alterações em sistemas de plataformas digitais, mudanças legislativas, para levar a contento a proposta da regularização fundiária.

Existem lacunas acerca de alguns requisitos do instituto de Mediação merecendo tratamento de sua aplicação transversal metodológica de instrumentos à serem utilizados pelos técnicos e instituições, estabelecendo as estratégias de ênfase na participação popular e cooparticipação de entidades públicas e privadas na solução dos casos, com a descrição dos limites de responsabilidades dos agentes públicos no ato de tomada de decisões deliberativas de políticas públicas afeitas as questões fundiárias nos municípios.

Por conseguinte, cumpre essa nova modalidade de mediação fundiária versar sobre formatos de (re) solução de conflitos ambientais, com novas práticas descentralizadas e desconcentradas reguladas, para o cumprimento da racionalidade do atendimento e ser- 
viços fundiários, em favor da distribuição de moradia, contribuindo com a diminuição das desigualdades e da pobreza, cumprindo com o objetivo basilar de pacificação dos conflitos socioambientais e fundiários nas cidades brasileiras.

\section{NOTAS}

1. A expressão de teoria de conflito misto é propositadamente sugerida pela acepção original da palavra misto ou misturado. A acepção de misto define diversas naturezas representadas por um meio termo entre duas coisas correlatas e interconectadas, sem perder a sua essência e mantendo a natureza de cada origem e formação do instituto ou instituição, chegando-se a uma proposta de formação de um terceiro elemento. O que difere da concepção de conflito híbrido em que a acepção original da palavra híbrido leva a união de elementos ou fatores, tornando um elemento distinto e novo, abandonando o caráter autônomo originário da natureza pertencentes a composição de algo diferente.

2. ADR - Alternative Dispute Resolution.

3. La propiedad urbana y rural en el Perú, debe ser de acuerdo a ley, un mecanismo impulsor del desarrollo integral: empresa, capital, gerencia, tecnología y como consecuencia de económico, social y cultura, en el corto y mediano plazo. El Decreto Legislativo 803 crea con este objetivo el sistema de formalización de la propiedad, integrado por COFOPRI, REGISTRO PREDIAL URBANO, FOPROP y TRIBUNAL ESPECIAL DE LA PROPIEDAD, que pretenden garantizar un eficiente y activo proceso de titulación a favor de los propietarios de predios urbanos sin documentos que acrediten su domínio. El derecho de los pobladores a tener títulos de propiedad, debe hacerse realidad en armonía a las disposiciones de la nueva ley, de manera que los inmuebles formalizados sirvan de garantía real suficiente para la obtención de créditos en los asentamientos humanos urbano marginales, urbanizaciones populares de interés social, centros poblados, asociaciones y cooperativas de vivienda (TORRES, 2009, p. 4-10).

4. Disponível em: https://www.wteamup.com/margov. Leitura na íntegra do Projeto e do sistema de gerenciamento de informações na Faculdade de Ciências e Tecnologia de Lisboa (FCTL - Portugal).

\section{REFERÊNCIAS}

ALMEIDA, Rafael Alves. Tribunal Multiportas: investindo no capital social para maximizar o sistema de solução de conflitos fundiários urbanos no Brasil. Rio de Janeiro: Fundação Getúlio Vargas, 2012.

ALVES SILVA, Franklyn Roger; ESTEVES, Diogo do Couto. A Nova Disciplina da Legitimação Extraordinária da Defensoria Pública no Novo Código de Processo Civil. In: DIDIER JUNIOR, Fredie; SOUZA, José Augusto Garcia de (coord.). Repercussões do Novo CPC. Salvador: Juspodivm, 2015. v. 5, Defensoria Pública, p. 313-344.

ALUTT, Antonio Garcial. Sustainability in the 21st Century - The Power of Dialogue. 2010.

BARROSO, Luís Roberto. Judicialização, ativismo judicial e legitimidade democrática. Revista de Direito do Estado, Salvador, ano 4, n. 13, p. 71-91, jan./mar. 2009.

CAFRUNE, M. A judicialização dos conflitos urbanos-ambientais na América Latina. Revista Direito\&Práxis, Rio de Janeiro, v. 7, n. 14, p. 376-396, jun. 2016. Disponível: https://www.researchgate. net/profile/Marcelo_Cafrune/publicati18on/303401771_Mediacao_de_Conflitos_Fundiarios_Urbanos_ do_Debate_Teorico_a_Construcao_Politica/links/5740dbac08ae298602ebb894.pdf?origin=publication_ detail. Acesso em: 19 out. 2016. 
CHACUR, R. L. Q.; OLIVEIRA, C. M. Modelo Descentralizado de Mediação para Resolução de Conflitos de Reforma fundiária urbana. Revista de Formas Consensuais de Resolução de Conflitos Brasília, Brasília, v. 3, n. 1, p. 36-50, jan./jun. 2017. XXVI Encontro Nacional de Pesquisa de Pós-graduação CONPEDI, 2017, Brasília, DF.

CHACUR, R. L. Q.; OLIVEIRA, C. M. Ocupação de espaços urbanos: a Ciência e a filosofia em tempos de Democracia. 2018. Simpósio Internacional sobre Direito Atual, Universidade Lusófona do Porto, Porto, 2018.

CHACUR, R. L. Q.; OLIVEIRA, Celso Maran de. Novo Código de Processo Civil versus a Judicialização para a Implementação das Políticas Públicas do Meio Ambiente. In: I CONGRESSO NOVOS DIREITOS, 2015, São Carlos. Anais. São Carlos: [s. n.], 2015.

CHACUR, R. L. Q.; OLIVEIRA, C.M. O. Novo Código de Processo Civil e as ações possessórias contra coletividades: avanços ou retrocessos. In: CONFERENCE: I CONGRESSO INTERNACIONAL DE CIÊNCIAS JURÍDICAS DA FACULDADE DE LONDRINA, 2017, Pavilhão Londrina Shopping, Londrina. Anais de Evento. Londrina, [s. n.], 2017. DOI: 10.13140/RG.2.2.28846.20808.

CEBOLA, Cátia. Legal impact of robots in civil liability and taxation: wat we know, trends and challenges. CM Cebola, C Sa, JL Martins, TA Ramalho. Economic and Social Development: Book of Proceedings, 2020, 135-143.

FONSECA, Rui Brito et al. Ambiente, Ciência e Cidadãos. Portugal: Edição Esfera do Caos, 2015.

FONSECA, Clécio de Jesus; SILVA, Gabriela Mateus de Fontes; MARQUES, Leandro de Souza; BARBUDA, Lucas; CASTRO, Cassio Marcelo Silva. Importância do SIG para Cadastramento Territorial e Planejamento Rural no Brasil. Artigo de Revisão. C\&D-Revista Eletrônica da Fainor, Vitória da Conquista, v. 9, n.1, p.74-88, jan./jun. 2016.

FISCHER, Roger; PATTON, Bruce; URY, William. Como chegar ao sim. Rio de Janeiro: Editora Imago, 1994.

KMIEK, Keenan D. The origin and current meanings of judicial review. Califórnia Law Reviw, oct, 2004.

LOPES, André Luiz. A legitimidade ativa ad causam na ação popular ambiental. Revista Amagis Jurídica, [S.I.], n. 8, p. 175-190, ago. 2019. ISSN 2674-8908. Disponível em: https://revista.amagis.com. br/index.php/amagis-juridica/article/view/132. Acesso em: 16 mar. 2020.

MARSHALL, William P. Conservatives and Seven sins of judicial activism. University of Colorado, Law Review, [S.I.], v. 73, n. 4, p. 37, set. 2002.

REALE, Miguel. Lições preliminares de Direito. 27. ed. [São Paulo]: Saraiva, 2002.

REALE, Miguel. Teoria Tridimensional do Direito. 5. ed. [São Paulo]: Editora Saraiva, 1994.

SIX, Jean François Six. Dinâmica da Mediação. Tradução Agda Arruda Barbosa, Gisele Groeninza de Almeida e Eliana Riberti Nazareth. Belo Horizonte: Del Rey, 2001.

TARTUCE, Fernanda. Mediação para Resolução de Conflitos. São Paulo: Revista dos Tribunais, 2016. 
VASCONCELOS, Lia; CASER, Úrsula; SILVA, Flávia; COELHO, Marilisa; SÁ, Rita; GONÇALVES, Graça; PEREIRA, Maria João Ramos; FERREIRA, José Carlos; PAINHO, Marco; DIAS, Fernando; CALBET, Oscar Vidal; OLIVEIRA, Tiago Humberto. Collaborative Governance in Marine Protected Areas - the Eco-Social Dialogue in the Empowerment of Changing Agents for the Sustainability of the Oceans. In: VASCONCELOS, Lia (coord.). Sustainability in the 21st century - The Power of Dialogue. [S.I.]: MARGov - Collaborative Governance of Marine Protected Areas, 2015, p 23-32. (ISBN 978-989874558-3).

Recebido em: 10/03/2021

Aceito em: 15/07/2021 